\title{
The Endomarketing as a strategic tool in the process of improvement in an information technology company
}

\author{
Daniela Mesquita da Silva ${ }^{1}$; Leiliane do Rosário Souza de Vasconcelos Dias ${ }^{1}$; Marleson da Silva Guimarães ${ }^{1}$ \\ ${ }^{1}$ Centro Universitário do Norte (UNINORTE). Av. Joaquim Nabuco, 1469, Centro. Manaus-Amazonas-Brasil. CEP: 69025-290. \\ Tel.: + 55 (92) 3212-5000. \\ (mesquita_danielamta@hotmail.com, leiliane.rodrigues18@gmail.com,m.guimaraessilva@ hotmail.com)
}

\begin{abstract}
Internal communication is also considered the main internal marketing tool, it is the communication effort to establish channels that enable relationship managers to their employees, as among elements that make this public. The objective of this article is to evaluate the development of internal communication through internal marketing actions in an information technology company. The methods and techniques used were a case study and document research as a methodology to obtain the data necessary for the development of this study. The results show that the company makes use of internal marketing actions as a strategic tool in the midst of their decisions, while internal communication needs to be revised a few detours and centralization in the process.
\end{abstract}

Keywords: Communication; internal public; success; internal marketing.

\section{O endomarketing como ferramenta estratégica no processo de melhoria em uma empresa de tecnologia da informação.}

\begin{abstract}
RESUMO
A comunicação interna também é considerada o principal instrumento de endomarketing, que se trata do esforço da comunicação para estabelecer canais que possibilitem o relacionamento dos gestores com os seus colaboradores, como entre os próprios elementos que integram este público. O objetivo do artigo é avaliar o desenvolvimento da comunicação interna por meio das ações de endomarketing em uma empresa de tecnologia da informação. Os métodos e as técnicas utilizadas foram um estudo de caso e pesquisa documental como metodologia, para obter os dados necessários para o desenvolvimento deste estudo. Os resultados encontrados mostram que a empresa faz uso das ações de endomarketing como ferramenta estratégica em meio a suas decisões, embora na comunicação interna precise ser revisto alguns desvios e centralizações no processo.
\end{abstract}

Palavras-chaves: Comunicação, público interno, sucesso, endomarketing.

\section{INTRODUÇÃO}

A forte tendência da globalização da economia e unificação dos mercados influência a forma de se pensar a comunicação nas organizações. [1] " diz que sem a comunicação, todas as relações estabelecidas entre as pessoas, e os diversos grupos humanos, seriam impossíveis. "A partir disso o Endomarketing se torna uma importante ferramenta de gestão como forma de alinhamento para a visão dos seus objetivos. Conforme [2] "o Endomarketing hoje é visto como um meio de diminuir o isolamento departamental, sem muitos atritos internos e superando resistências a mudanças".

A pesquisa justifica-se por meio da competitividade no setor de tecnologia da informação que vem se expandindo no Brasil, onde o fator humano (colaboradores) precisa ser motivado, treinado e posicionado de acordo com os pontos estratégicos da organização. A principal contribuição vem a ser a elaboração de uma apresentação coerente dentro e fora da empresa, por meio dos objetivos que se baseia "na manutenção de um ambiente de trabalho que proporcione motivação, valorização e reconhecimento das pessoas; [...] e a criação de canais de comunicação entre todos, independente do nível hierárquico, gerando assim uma melhoria nos relacionamentos" [3]. A comunicação interna como também a externa é de vital importância para a sobrevivência das organizações no mercado em que atua, pois é o elo entre clientes internos e externos da empresa, conforme define [1] "a comunicação dentro da empresa contribui para a definição e concretização de meta e objetivos, além de possibilitar a integração entre seus componentes, departamentos e áreas". 
Daniela M. da Silva, Leiliane do R. S. de V. Dias, Marleson da Silva. G./ITEGAM-JETIA Vol.02, Nº 07, pp.84-89. Setembro, 2016.

Diante disso formula-se a seguinte questão: Qual o posicionamento da empresa de TI no processo de comunicação interna utilizando as ferramentas de endomarketing?

\section{REVISÃO BIBLIOGRÁFICA}

\section{II.1 O ENDOMARKETING E SEUS CONCEITOS.}

O Endomarketing tem inicio com a definição dos domínios do Marketing e dos programas de Qualidade nas empresas. Atualmente todas as organizações têm focado no empenho total do seu público interno, para o alcance do sucesso, tornando-o um aliado e fomentado a ideia de que o sucesso está ligado ao sucesso da empresa. A valorização do fator humano é o que traz a resposta imediata à organização mediante as mudanças imprevisíveis, pois colaboradores motivados caminham junto com a empresa.

De acordo com [4] define "o endomarketing como uma atividade de apoio às funções da organização, definidos pela inclusão das pessoas por meio da informação coesa e distribuída de forma ágil”.

Já [2] "afirma que o endomarketing é ações gerenciadas de marketing eticamente dirigidas ao público interno das organizações e empresas focadas no lucro, observando condutas responsáveis". Ou seja, pôr na mente empresarial que cada colaborador é fundamental para atingir o sucesso, compartilhando os objetivos empresariais e sociais da organização.

\section{II.2 O PÚBLICO INTERNO.}

Organizações bem-sucedidas responsabilizam seus gerentes de áreas de suporte com a atribuição chave de ajudar os funcionários da linha de frente a realizar um reconhecido serviço de qualidade aos clientes e confirmado por eles, "colaborando internamente com os outros departamentos" [5].

"Integrar a noção de cliente e seus valores ao público interno que compõem a estrutura organizacional, propiciará uma melhoria na qualidade de produtos e serviços, com produtividade pessoal e de processos"[6].

Divide-se o público interno em dois grupos: as chefias e os colaboradores comuns, estes divididos em apoio e linha de frente. Pode-se esclarecer que a linha de frente se diferencia do pessoal de apoio no sentido que este atende o público externo, e tem como responsabilidade transmitir ao consumidor a imagem da empresa, de forma clara e objetiva, da melhor maneira possível, mas ambos devem necessariamente receber o mesmo nível de informação e treinamento, pois trabalham diretamente com o cliente, seja ele interno ou externo.

\section{II.3 O ENDOMARKETING E A COMUNICAÇÃO INTERNA}

Como principal produto da comunicação interna, a informação, tem início no alto da estrutura organizacional e é distribuída aos níveis por meio da responsabilidade de quem cria e detêm o produto da comunicação, ou seja, a alta direção da empresa. Como forma de acompanhar o andamento da informação pelas diversas áreas, se faz necessário uma atitude proativa, que consiste em procurar o cliente interno para obter o feedback em relação ao serviço que está sendo prestado.

Para [7] diz que "um bom feedback identifica os aspectos mais importantes do relacionamento e do serviço, de acordo com a percepção da área-cliente e, principalmente, com o efeito sobre o cliente externo, isto é, consumidor final". A eficiência da linha de comunicação tem relação com o grau de motivação de um funcionário, pois funcionário motivado e mobilizado tem motivos de sobra para entrar em ação, e a comunicação é justamente o que o abastece e o mantém jogando 'com amor a camisa'.

\section{II.4 AS INFLUÊNCIAS DO ENDOMARKETING NO AMBIENTE ORGANIZACIONAL}

As empresas que procuram diferencial no mercado apostam fortemente na comunicação de seus objetivos para com o trabalho, pois não se deve realizar a comunicação em um único sentido, mas sim, como um esquema, com objetivo da construção de relacionamentos com o público interno, harmonizando e fortalecendo as relações pessoais. [8] diz que "Endomarketing é, portanto, uma das principais ferramentas de gestão de pessoas nas empresas que buscam não apenas sucesso em termos de mercado, mas a perenização".

Desse modo, entende-se que o endomarketing é um reflexo positivo da maneira como as empresas encaram sua comunicação interna, pois propicia condições para que a criatividade venha à tona trazendo benefícios para todos. Nesse sentido, [9] afirmam que "uma rede de comunicação tem de constituir parte do cotidiano da empresa, de sua cultura organizacional".

\section{II.5 PROGRAMAS DE ENDOMARKETING: IMPLANTAÇÃO}

É fundamental ter um diagnóstico, só a partir de uma avaliação cuidadosa e sistemática do ambiente interno da empresa um programa de endomarketing pode ter êxito. Essa avaliação do ambiente interno traz consigo aqueles mesmos fatores presentes na avaliação estratégica do ambiente externo, conhecidos como SWOT, por meio de uma radiografia interna da empresa que leva em conta suas forças, suas fraquezas, as oportunidades existentes e as ameaças a seu desempenho.

O Quadro 1 mostra todo o caminho para identificar o estrangulamento da empresa com as perdas de oportunidades. Definindo o objetivo empresarial, ou a oportunidade de mercado, parte-se para uma autoanálise e uma verificação de recursos existentes. 
QUADRO 1. Quadro contextual para aplicação de endomarketing em serviços

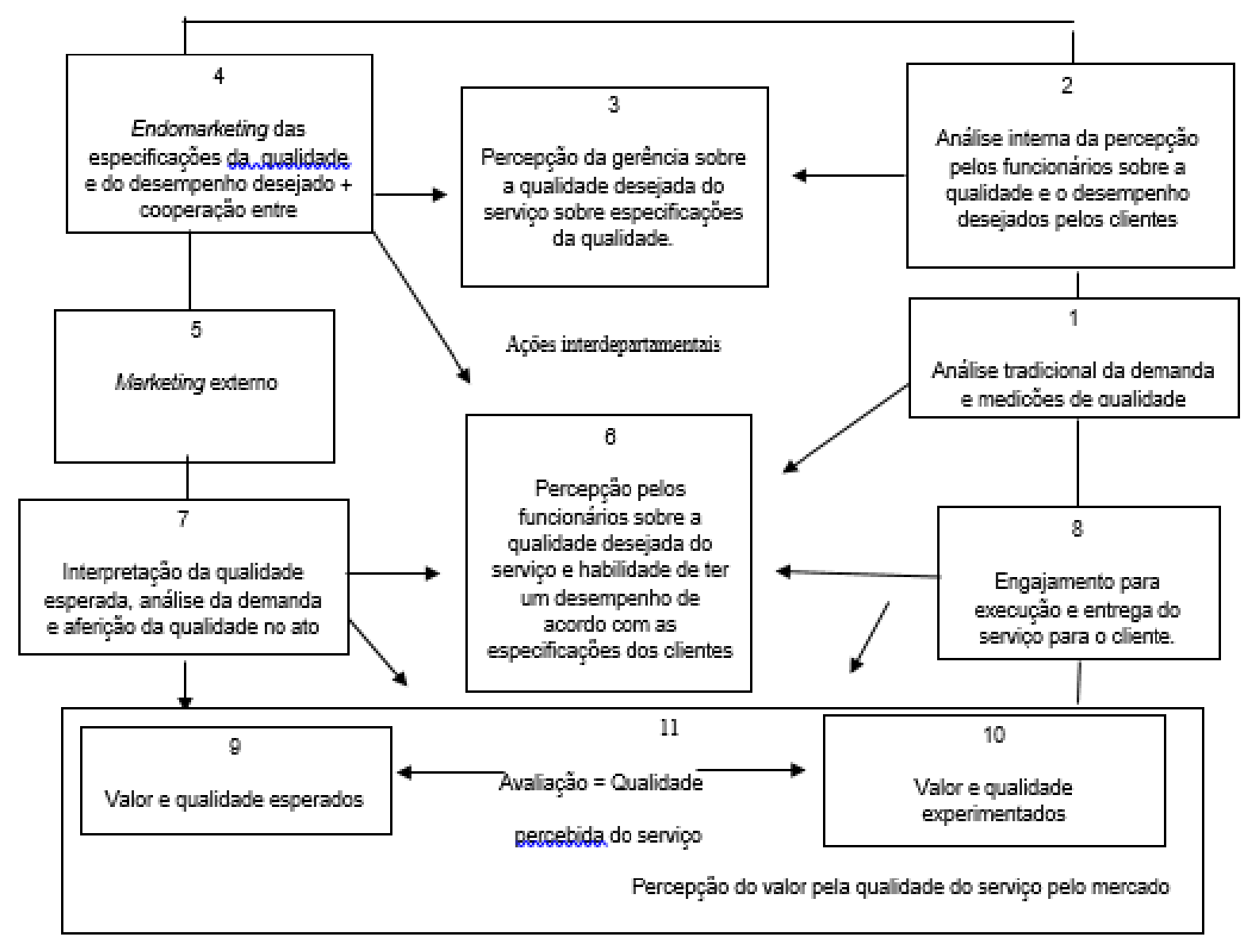

1

Fonte: [2] .

\section{MATERIAIS E MÉTODOS}

Os métodos propostos têm subordinação direta com os objetivos, segundo [10] este item é considerado como "[...] o conjunto das atividades sistemáticas e racionais que [...] permite alcançar os objetivos, traçando o caminho a ser seguido, constatando erros e auxiliando as decisões do cientista".

A metodologia utilizada para o desenvolvimento deste artigo será por meio de entrevista, de acordo com [11] "A entrevista tem como objetivo compreender os significados que os entrevistados atribuem às questões e situações relativas ao tema de interesse". É uma comunicação verbal entre duas ou mais pessoas com um nível de estruturação previamente determinado. Por meio de análise documental que trata de qualquer registro escrito que possa ser usado como fonte de informação, conforme diz [11] "o uso de documentos no estudo de caso tem como função mais importante valorizar as evidências oriundas de outras fontes [...] em formato de registro ordenado e de vários aspectos da vida social". E por fim um Estudo de Caso, abordando o tema de endomarketing dentro de uma empresa de TI da cidade de Manaus, onde [11] diz que "o estudo de caso com características descritivas apresenta um relato detalhado de um fenômeno social, que envolvendo configuração, estrutura, atividades, mudanças no tempo e relacionamento com outros fenômenos".

A investigação será conduzida por meio de uma revisão bibliográfica, onde serão consultados vários livros da área com o propósito de se obter, através destas fontes, um número expressivo de dados e informações que nos possibilite o agrupamento das ideias, para que essas possam ser tratadas e analisadas de forma a responder às questões levantadas. Com o objetivo de diagnosticar a situação da empresa de tecnologia da informação em nível de comunicação e marketing interno, elaborou-se dois instrumentos de pesquisa distintos - um de Entrevista e um outro de Pesquisa de Clima Organizacional, além da pesquisa documental realizada.

\section{ESTUDO DE CASO}

Nesta seção são apresentados os resultados da pesquisa avaliativa para efetivar as ações de endomarketing na empresa de TI abrangendo os principais horizontes da comunicação interna, por meio da análise dos dados obtidos pela entrevista e análise documental da empresa. 
Daniela M. da Silva, Leiliane do R. S. de V. Dias, Marleson da Silva. G./ITEGAM-JETIA Vol.02, Nº 07, pp.84-89. Setembro, 2016.

\section{IV.1 PERFIL DA EMPRESA}

A empresa de TI encontra-se vinculada, à Secretaria de Planejamento e Desenvolvimento Econômico (SEPLAN) e cumpre seu papel na área de varejo do conglomerado tecnológico, cujo seu objetivo é a prestação de serviços especializados em Tecnologia da Informação e Comunicação. A força de trabalho da empresa é composta por 485 funcionários, entre eles funcionários efetivos, terceirizados e estagiários, onde estão assim distribuídos conforme mostra a tabela 1.

Tabela1: Perfil do quadro pessoal - funções.

\begin{tabular}{l|c}
\multicolumn{1}{c|}{ Função } & $\mathbf{N}^{\mathbf{0}}$ de Funcionários \\
\hline Analista & 20 \\
Administrativo & 139 \\
\hline Analista de TI & 46 \\
\hline Assistente 180h & 75 \\
\hline Assistente 220h & 2 \\
\hline Auxiliar 180h & 12 \\
\hline Auxiliar 220h & 1 \\
\hline Assistente Social & 86 \\
\hline Programador &
\end{tabular}

Dos funcionários $74 \%$ são homens e $26 \%$ são mulheres. Com relação a faixa etária $2 \%$ possuem acima de 60 anos, $36 \%$ possuem acima de 40 anos e $62 \%$ possuem até 30 anos. O perfil do nível de escolaridade dos colaboradores da empresa está assim distribuído, como mostra a figura 1.

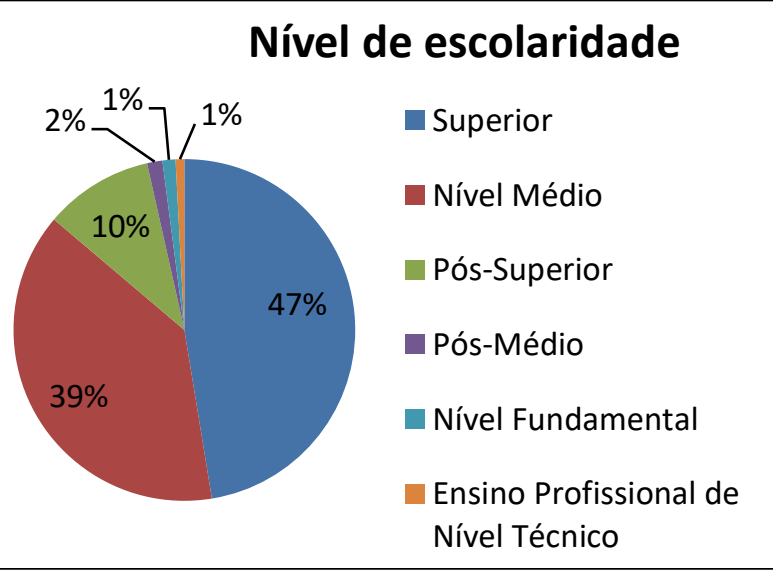

Figura 1 - Nível de Escolaridade dos funcionários

Fonte: Os autores, (2016).

\section{IV.2 PESQUISAS E COMUNICAÇÃO INTERNA}

Para avaliar a comunicação interna foi elaborado um roteiro de entrevista com 9 questões, sobre as ferramentas disponibilizadas para facilitar a comunicação na instituição e um questionário sobre o clima organizacional da empresa. Por meio da entrevista realizada com a Assessora de Comunicação, constatou-se que a empresa se preocupa com estreitamento dos laços organizacionais entre seus colaboradores, contribuindo com a qualidade de vida dos mesmos. Os objetivos principais são o bem-estar, a eficiência, a lucratividade e expansão da empresa, oferecendo aos seus funcionários reconhecimento, oportunidade de crescimento, benefícios, treinamento e gestão participativa.

A empresa conta também com avaliação de desempenho, para avaliar o desempenho do colaborador a cada ano. No que diz respeito aos treinamentos, a Analista de Treinamento e Desempenho destaca que "juntamente com o Setor de Perfil e Desempenho, a empresa realiza todos os anos um cronograma de treinamentos para cada setor, voltados para a área de atuação". No decorrer da entrevista, questionamos alguns funcionários sobre a frequência que leem as notícias disponibilizadas pela instituição e cerca de $63 \%$ leem diariamente e $37 \%$ afirmam que leem em dias alternados.

Sob o comando da ASCOM (Assessoria de Comunicação), a empresa conta com vários canais de comunicação interna, são eles: Intranet, TV Institucional, E-mail corporativo, SACP (Serviço de atendimento ao cliente interno e externo). A figura 2 mostra a satisfação dos colaboradores em relação a essas ferramentas:

Com a análise dos dados da figura 2, constatou-se que os colaboradores que se demonstram pouco insatisfeitos, insatisfeitos e muito insatisfeitos alegam que a falta de agilidade na comunicação prejudica a execução dos trabalhos rotineiros.

\section{Comunicação Interna}

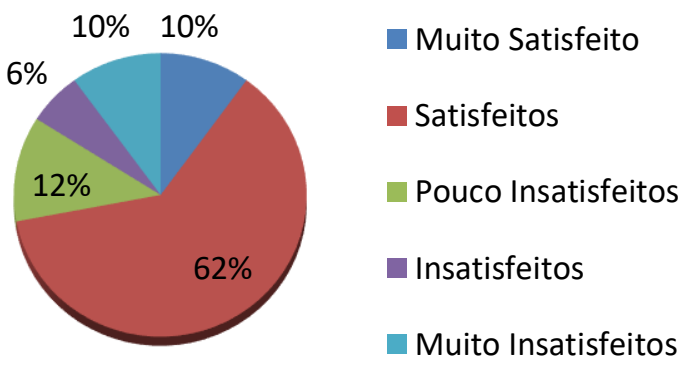

Figura 2: Nível de satisfação com a comunicação interna. Fonte: Os autores, (2016).

\section{IV.3 DADOS DO CLIMA ORGANIZACIONAL.}

“A pesquisa de clima organizacional é um dos principais instrumentos de avaliação das políticas de gestão de pessoas e estratégicas de endomarketing empregadas" [12]. Pesquisas de clima são realizadas com rigor técnico necessário para que permitam utiliza-las efetivamente como instrumento de análise ou ferramenta de controle, gerando resultados que podem induzir a maus julgamentos, positivos ou negativos, sobre o clima organizacional. "A cultura organizacional envolve valores normas e crenças sobre o apropriado comportamento e atitudes dentro da organização" [13].

A pesquisa de clima organizacional foi realizada com os funcionários da empresa de TI da cidade de Manaus. Apresentação 
dos dados obtidos nesta pesquisa segue um formato de perguntas e suas respectivas análises, o que nos permitiu diagnosticar o ambiente no qual a empresa realiza os seus serviços. Para que os colaboradores pudessem fazer relação às ações de endomarketing a sua percepção, foram distribuídos questionários com perguntas específicas sobre o assunto, seguindo os aspectos de relacionamento interpessoal, salários e benefícios, liderança e ambiente de trabalho.

No que diz respeito ao relacionamento interpessoal figura 3 , verifica-se que $49 \%$ concordam com a forma de relacionamento entre os colaboradores dentro da empresa, $36 \%$ concordam parcialmente, pois falta cooperação entre os colaboradores dentro do setor, $8 \%$ não concordam, ressaltando que a relação da diretoria com os demais colaboradores não é harmoniosa e 7\% não deram sua opinião.

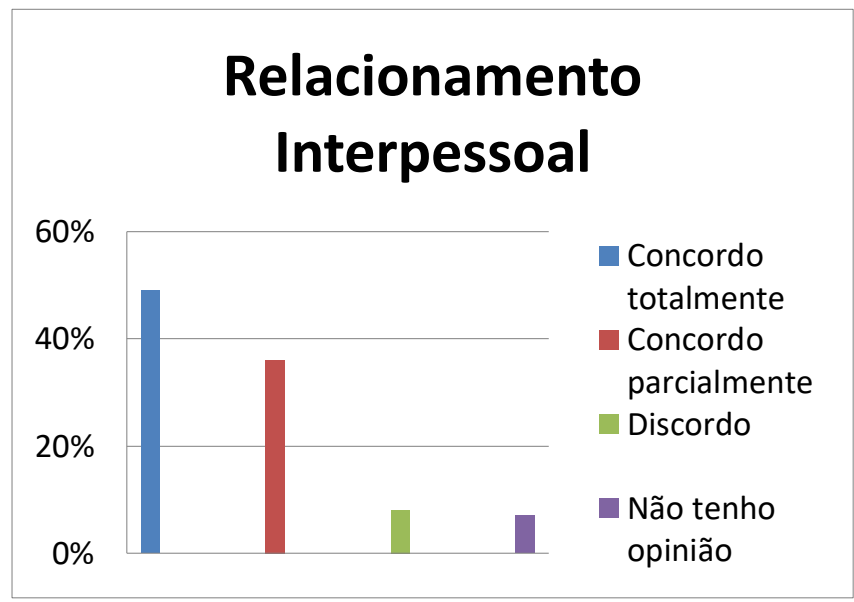

Figura 3: Análise do Relacionamento.

Fonte: Os autores, (2016).

Em relação aos salários e benefícios oferecidos figura 4, $41 \%$ dos colaboradores estão satisfeitos com os benefícios oferecidos o que reforça sua permanência na empresa, 37\% ressaltam que os salários oferecidos são competitivos com o do mercado, o que os deixam parcialmente satisfeitos, $16 \%$ estão insatisfeitos, pois alegam que faltam critérios claros para a promoção funcional e $6 \%$ não deram sua opinião

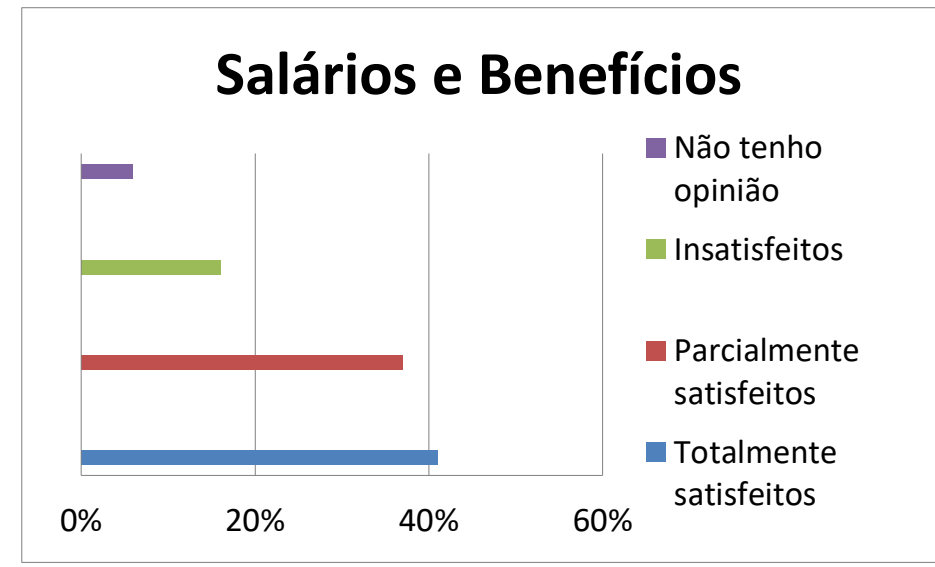

Figura 4: Análise dos Salários e Benefícios interpessoal. Fonte: Os autores, (2016).
Outro aspecto pesquisado foi a liderança figura 5 , onde $46 \%$ dos funcionários concordam totalmente com a forma de liderar, pois têm a liberdade de expressar suas opiniões diferentemente a dos superiores imediato, $40 \%$ alegam falta de clareza na comunicação o que os deixa parcialmente satisfeitos, $9 \%$ consideram-se insatisfeitos devido a falta de motivação no setor para a realização das tarefas e $5 \%$ não deram sua opinião.

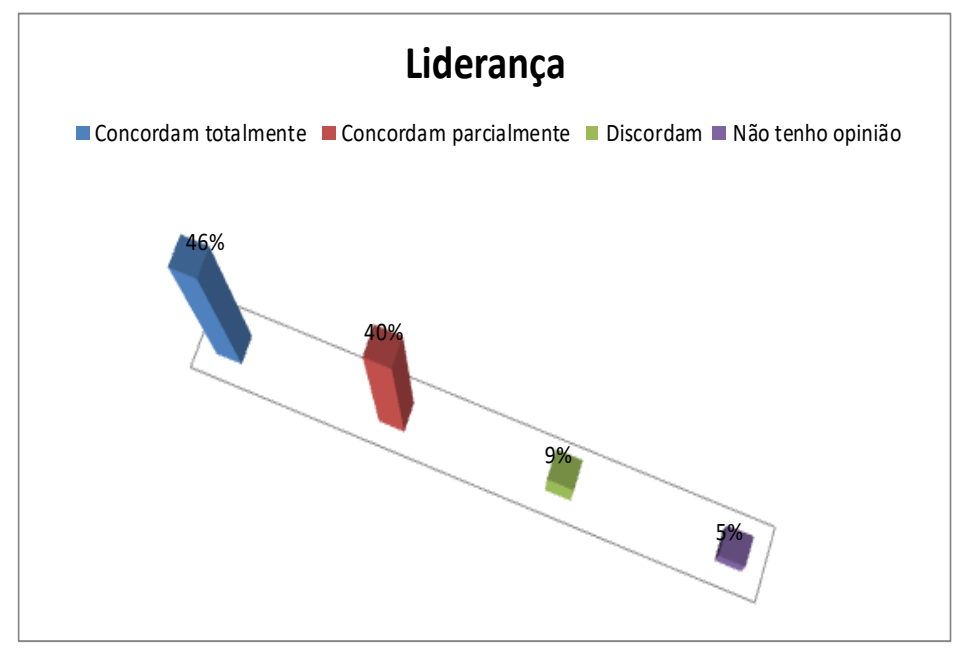

Figura 5: Análise da liderança.

Fonte: Os autores, (2016).

Em relação ao ambiente de trabalho figura 6, 31\%dos colaboradores estão totalmente satisfeitos com o ambiente organizacional, $41 \%$ afirmam que as condições de segurança física e lógica são adequadas a uma empresa de TIC o que os deixa parcialmente insatisfeitos, $23 \%$ estão insatisfeitos, pois o mobiliário não é ergonomicamente projetado para o conforto, agilidade $\mathrm{e}$ praticidade no ambiente de trabalho e $5 \%$ não tem opinião.

\section{Ambiente de Trabalho}

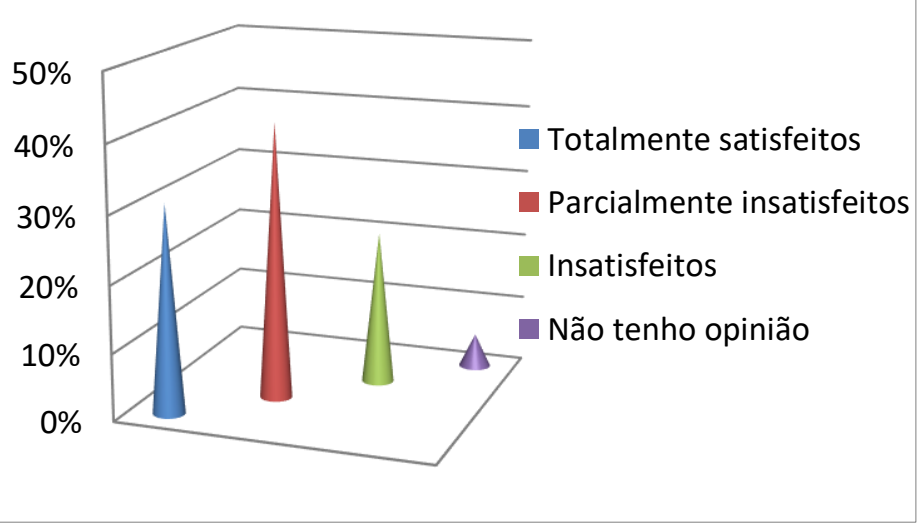

Figura 6: Nível de satisfação do ambiente de trabalho Fonte: Os autores, (2016). 
Daniela M. da Silva, Leiliane do R. S. de V. Dias, Marleson da Silva. G./ITEGAM-JETIA Vol.02, No 07, pp.84-89. Setembro, 2016.

\section{IV.4 ANÁLISE, RESULTADOS E DISCUSSÕES}

Em face aos grandes desafios, das transformações e incertezas do mundo globalizado, as organizações atravessam atualmente um período de grandes mudanças, abandonando o ciclo da revolução industrial para incorporar uma nova era, marcada pela velocidade de informações.

A empresa de tecnologia da informação mediante a um processo continuado de gestão de pessoas vem obtendo sucesso no que se refere a construção de um ambiente de trabalho agradável, cooperativo, inovador e cumpridor de metas. Pode-se notar que a empresa investe em treinamento e formação de liderança que contribuem para garantir que as decisões corporativas sejam aplicadas no ambiente de trabalho.

De acordo com os resultados obtidos nos dados do clima organizacional, contatou-se que, apesar de alguns aspectos não atenderem todos os entrevistados, os colaboradores demonstraram que se encontram satisfeitos com as politicas de endomarketing adotadas pela empresa. Desse modo os resultados alcançados mostram que o uso do endomarketing como ferramenta estratégica, alinha a gestão de pessoas com os interesses da organização e seus colaboradores para em comum atingirem um diferencial competitivo gerando valor no mercado e na sociedade.

Com base nos aspectos e variáveis pesquisadas tem-se a condição de que a filosofia da empresa vem sendo disseminada junto aos seus colaboradores, baseando-se na premissa de que o desenvolvimento pessoal e profissional só ocorre se o ser humano tiver qualidade de vida, o que contribui para tornar a empresa ainda mais saudável e motivada.

\section{CONCLUSÃO}

Com base nos objetivos gerais e específicos, apresenta-se os resultados alcançados pela pesquisa concluindo-se que as ações e ferramentas do endomarketing utilizados na empresa são efetivas. Essa afirmação é baseada nos resultados encontrados nos formulários de pesquisa que analisaram os seguintes indicadores: relacionamento interpessoal, salários e benefícios, liderança e ambiente de trabalho. A empresa pesquisada promove ações próprias de endomarketing como forma de motivar e manter os funcionários comprometidos com as metas e objetivos. Como exemplo, podemos citar as campanhas internas de criação de mascote como marca sustentável em TI, que premia os funcionários valorizando suas criações com brindes e publicação na intranet da empresa.

Por fim, os resultados apresentados no estudo de caso, por meio de todos os dados e informações obtidas, são apropriados concluir que as ações de endomarketing refletem no modo de promover o crescimento sustentável dos negócios e a retenção dos talentos encontrados na empresa, fazendo referência a diversos aspectos da cultura ou realidade da organização. Considerando em última análise, endomarketing reforça os valores que compõem a identidade empresarial e contribui para que estes sejam percebidos, interna e externamente, com maior fidelidade e confiabilidade.

\section{AGRADECIMENTOS}

Ao Centro Universitário do Norte (UNINORTE), pelo apoio a realização desta pesquisa.

\section{REFERENCIAS BIBLIOGRÁFICAS}

[1].PIMENTA, Maria Alzira. Comunicação Empresarial. 3 ed. Campinas:Atlas, 2010.

[2].BEKIN, S. F.; Endomarketing: como praticá-lo com sucesso. São Paulo: Prentice Hall, 2004.

[3] KOTLER, P.; Administração de Marketing: a edição do novo milênio. Tradução Bazán Tecnologia e Lingüística; São Paulo: Prentice Hall, 2000.

[4] COSTA, Daniel. Endomarketing Inteligente: pensada de dentro pra fora. Porto Alegre: Dublinense, 2003.

[5] D'Angelo, B. Social media community management: Implications for business communication curriculum. Proceedings of the 75th Annual Convention of the Associationfor Business Communication. 2010 - Chicago, Illinois (available at http://businesscommunication)

[6] BRUM, A. M.; Endomarketing como Estratégia de Gestão/Encante seu Cliente Interno. Porto Alegre: L\&PM, 2005.

[7].SKORA, C. M.; Endomarketing: a importância da comunicação interna. Espaço Aberto, 2006

[8].BRUM, A. M. Endomarketing de A a Z: Como Alinhar o Pensamento das Pessoas à Estratégia de Empresa. 1. ed. Rio de Janeiro: Integrare Editora, 2010.

[9].CARnEVALli, V. M. L; TÓFANI, F.; Endomarketing Como Ferramenta Estratégica de Valorização do Cliente Interno. Disponível em: http://www.portaldomarketing.com.br. Acesso em 25 de março de 2014 às $10 \mathrm{~h} 10$.

[10].MARCONI, Marina de Andrade; LAKATOS, Eva Maria. Fundamentos de metodologia científica. 6. ed. São Paulo: Atlas, 2005.

[11].SILVA, Anielson Barbosa da.; Pesquisa qualitativa em estudos organizacionais: paradigmas, estratégias e métodos. São Paulo: Saraiva, 2006.

[12].COSTA, Daniel.; Endomarketing Inteligente: pensada de dentro pra fora. Porto Alegre: Dublinense, 2012.

[13].ROBBINS, S. P., \& LANGTON, N. Fundamentals of organizational behaviour. Toronto, ON: Pearson Education Canada.2005. 